\title{
FORECASTING MODEL OF AGRICULTURE COMMODITY OF VALUE EXPORT OF COFFEE: APPLICATION OF ARIMA MODEL
}

\author{
R.R. Erlina ${ }^{1}$, Rialdi Azhar ${ }^{2 \bowtie}$ \\ ${ }^{1}$ Department of Management, Faculty of Economics and Business, Universitas Lampung \\ ${ }^{2}$ Department of Accounting, Faculty of Economics and Business, Universitas Lampung

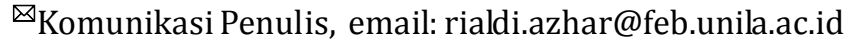 \\ DOI:http://dx.doi.org/10.23960/jtep-lv9i3.257-263
}

Naskah ini diterima pada 21 Juli 2020; revisi pada 14 Agustus 2020; disetujui untuk dipublikasikan pada 29 September 2020

\begin{abstract}
Indonesia is currently one of the largest coffee producers in the world, and involved in exporting coffee countries. The financial series data such as export value of coffee is highly volatile in both mean and variance. Thereby, the model of ARIMA with order $p, d$, q is one way to deal with error. The aim of this study is to determine the best-fitted ARIMA(p,d,q) model to forecast the monthly series of export of coffee from January 2005 to April 2020. The findings suggest that ARIMA(1,3,1) is the best-selected model due to its very significant $p$-value (less than 0.0001), which showed that the model is applicable for forecasting. The model is then used to establish the prediction of ExCof monthly data for the next 12 months. Further results on forecasting of the export value of coffee show an increasing trend.
\end{abstract}

\section{Keywords: ARIMA model, volatility, forecasting, commodity value, export of coffee}

\section{INTRODUCTION}

Currently, Indonesia is one of commodity producers of coffee in the world. As a matter of fact, $70 \%$ of commodity coffee in Asian countries is produced by small and traditional farmers (Oxfam et al, 2001). While the demand of coffee around the globe increases, the export value of Indonesian coffee shows an increasing trend. It is because on the downstream industry, there have been a coffee shop and coffee consumption has become a necessity in daily lives.

Xiong et al. (2015) showed in his empirical study that risk management, price speculation in particular, in commodity trading should be measured, calculated, forecasted, and analysed more accurately, since it might become a policy benchmark for decision makers and for trading value. In addition, the characteristic of export value of coffee is similar to time-series data set that has a complex and dynamic stability level, so it is interesting and challenging to be predicted.

This study is to assess time-series data of one export commodity in agriculture industry, which is historical export value of coffee from Indonesia. Time-series data is the sequence of observations over some intervals (Wei, 2006), either stationary or non-stationary. It then can be modelled by some certain analytical tools to have a fitted forecasting model (Tsay, 2014). One of which is Autoregressive Integrated Moving Average (ARIMA) model of order p,d,q. Autoregressive Integrated Moving Average (ARIMA) model is suggested to have a fitted measurement as a forecasting model. Azhar et al. (2020) used ARIMA assumption as statistical and analytical tool in modelling daily stock prices listed in Jakarta Islamic Index (JII).Meanwhile, a forecasting model can be divided into some specification of short-term, middle-term, and long-term (Montgomery et al., 2008). In fact, studies with short-term forecasting applying time-series data set shows relatively small level of error (Chen et al., 1995; Moghram \& Rahman, 1989; Virginia et al., 2018).

\section{MATERIALS AND METHOD}

The data used in this study are the export value of coffee (thousands of USD) obtained from Bank of Indonesia 2005 to 2020 . According to Sampson (2001), the first step in ARIMA 
modelling is to station the series, which is a fundamental concept. Therefore, it is a necessity to check the stationary of the series using the Augmented Dickey-Fuller (ADF) unit-root test by conducting the hypothesis where $\mathrm{H}_{0}$ equals to zero (Azhar et al., 2020). This is mathematically equated as follows:

ADF Test: $\quad t=\frac{\ddot{\vartheta}-1}{\operatorname{Se}(\vartheta)}$

$\mathrm{H}_{0}$ is rejected if $t$ and the p-value are less than 2.57 and 0.05 , respectively, at $95 \%$ confidence (Brockwell \& Davis, 2002). In addition to the ADF test, autocorrelation function (ACF) and partial autocorrelation function (PACF) are exhibited to have a clear picture of the stationary series. The test of ACF and PACF are also used to determine the data, which is a fundamental tool in identifying the ARIMA model for forecasting (Montgomery et al., 2008). Brockwell \& Davis (1991) analysed the equation of ARIMA model as follows:

$$
\phi_{p}(L)(1-L)^{d} \operatorname{ExCoF}_{t}=\alpha+\theta_{q}(L) \varepsilon_{t}
$$

where, $\phi_{p}(L)=\left(1-\phi_{1} L, \ldots, \phi_{p} B^{p}\right),(1-L)^{d} \quad$ is differencing of order $\mathrm{d}, \alpha$ is constant, $\varepsilon_{t}$ is residuals, $\mathrm{L}$ is the notational device for lags, and $\theta_{q}(L)=\left(1-\theta_{1} L, \ldots, \theta_{q} L^{q}\right)$.

However, by using SAS output, equation (2) is simplified as follows:

$$
\begin{gathered}
\operatorname{ExCof}_{t}=\alpha+\phi_{1} \operatorname{ExCof}_{t-1}+\ldots+\phi_{p} \operatorname{ExCof}_{t-p}+ \\
\theta_{1} \varepsilon_{t-1}+\ldots+\theta_{q} \varepsilon_{t-q}+\varepsilon_{t}
\end{gathered}
$$

There are two ways of scoring ARIMA model based on its log-likelihood and complexity, namely Akaike Information Criterion (AIC) and Schwartz Bayesian Criterion (SBC).

\section{RESULTS AND DISCUSSION}

\subsection{Data Descriptive and Stationarity Condition}

The study attempts to analyse monthly data of Indonesian Coffee Export from January 2005 to April 2020. Overall, as shown on Figure 1, the observed data fluctuates with high volatility until the end of study period. Starting from slightly more than 30 point (in thousands of USD), it gradually increased up to tenth data before it plummeted to reach just above 20. Afterwards, it moved up and down sharply, and it reached its peak on its $90^{\text {th }}$ data observation at around 160 point. The remaining behaviour data movement was also very volatile with the last data reaching only approximately 60 s point.

Further stage is to convert the non-stationary into stationary; otherwise, it becomes less effective to model the forecasting setting. In this stage, the technique that also supports the model is conducted by differencing the data with some certain lags.

Table 1 indicates probability value of zero mean is more than the acceptance value of 0.05 , showing the data set has not met the condition of stationary. Figure 2a of ACF and $2 b$ of PACF respectively also depict non-stationary as the

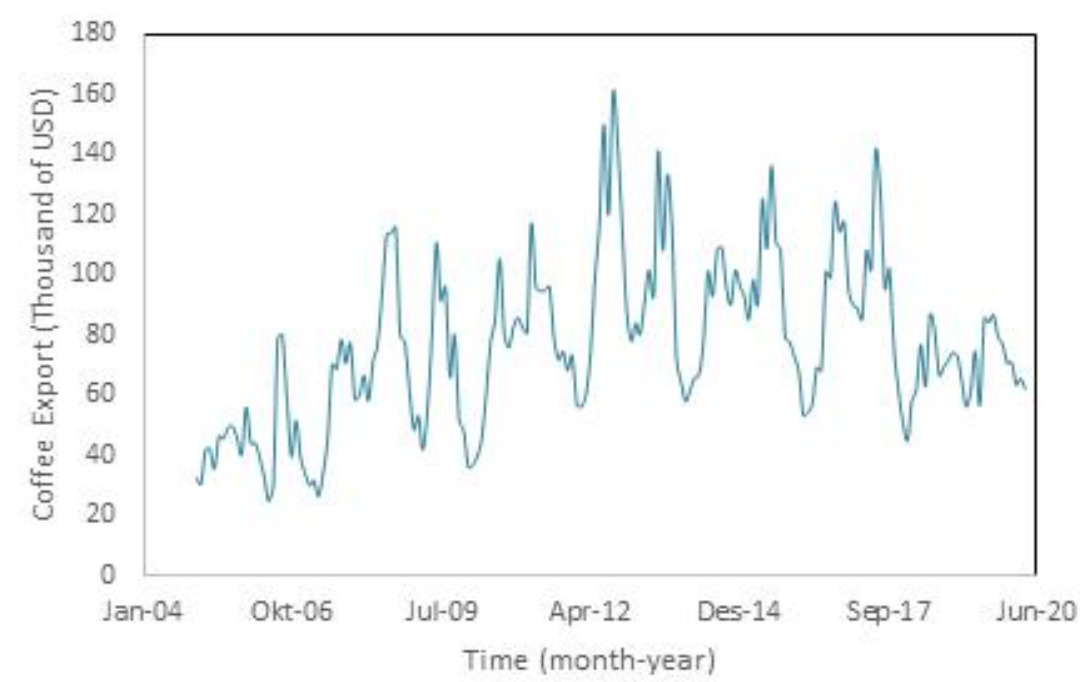

Figure 1. Data Plotting of Coffee Export 
Table 1. Augmented Dickey-Fuller Unit Root Tests

\begin{tabular}{lccccccc}
\hline Type & Lags & Rho & Pr $<$ Rho & Tau & Pr $<$ Tau & F & Pr $>$ F \\
\hline Zero Mean & 1 & -2.4151 & 0.2851 & -1.0442 & 0.2664 & & \\
Single Mean & 1 & -29.1905 & 0.0013 & -3.9079 & 0.0025 & 7.6515 & $<.0010$ \\
Trend & 1 & -33.4116 & 0.0028 & -4.0275 & 0.0095 & 8.2808 & 0.0040 \\
\hline
\end{tabular}

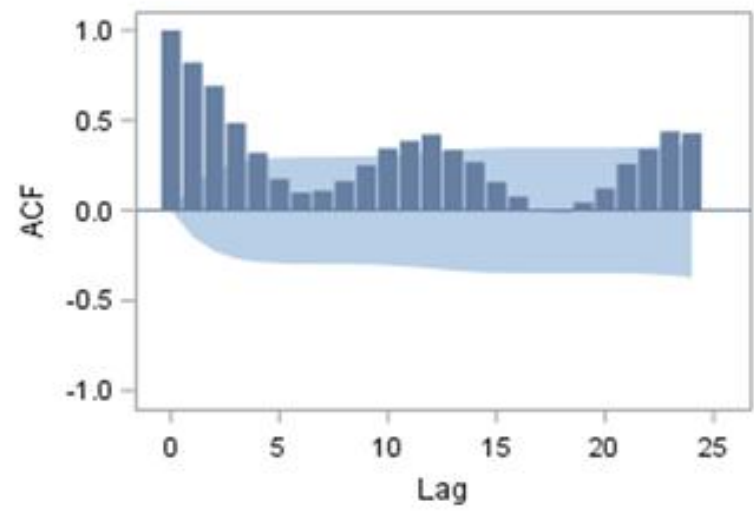

a

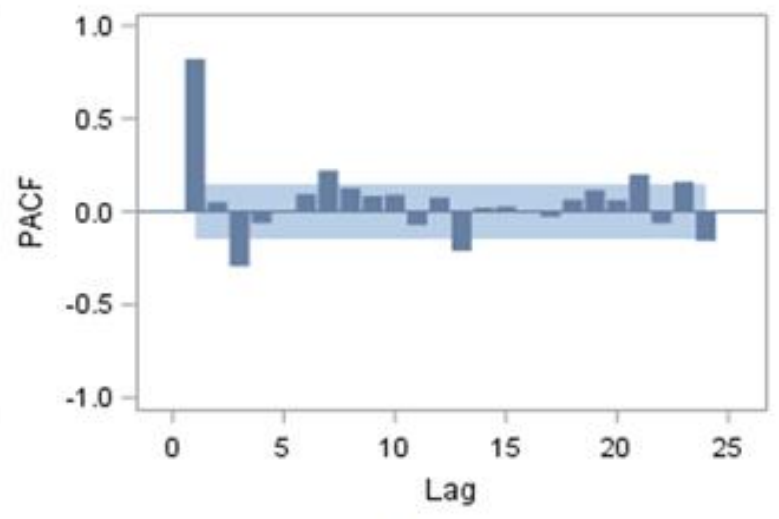

b

Figure 2. (a)Autocorrelation Function (ACF) and (b) Partial Autocorrelation Function (PACF)

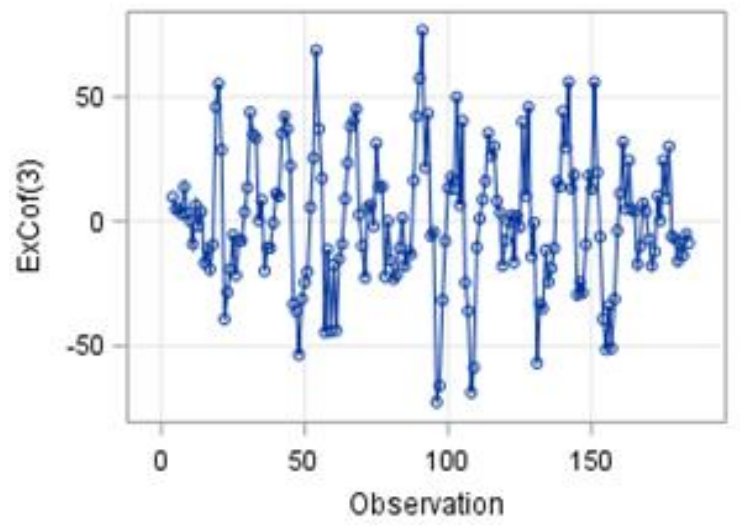

Figure 3. Residual Plot After Differencing 3 (d=3)

former experiences a decay movement while the letter has a value outside the acceptance region of zero.

\subsection{Stationary Transformation}

Furthermore, the behaviour data set has also shown a non-stationary condition, in which mean and volatility are not in around circle of zero. This can be proven statistically from test of Augmented Dickey-Fuller (ADF), ACF and PACF graphs.

Figure 3 shows that after differencing 3 , the plot data becomes at around zero. It should be noted that the data is not stationary with differencing 1 or 2 . The graph also demonstrates that the error predictions of the first 50 data are homogenous.
However, between 50 and 100 data it tends to be larger than at 2 standard deviation, and some are beyond the two standard errors, which are confirmed in Figure 1. Meanwhile, the last 50 data, the data set come back to have 1 standard deviation of residuals.

The transformed stationary is also supported with ADF test as well as the graphs of ACF and PACF as follows presented Table 2 and Figure 4. Table 2, and Figures $4 \mathrm{a}, 4 \mathrm{~b}$ are shown the stationary data after differencing $3(\mathrm{~d}=3)$, and it becomes stationary because ACF movement now is moving down faster, with a significant correlation of residuals, and p-value $<0.0010$. These show that the series has no 
autocorrelation after differencing because it is beyond the regression limit.

\subsection{Forecasting Model}

The stationary stage is followed by designing the ARIMA model that fits the forecasting data set. Therefore, Table 3 and 4 present the parameters of estimation for the ARIMA $(1,3,1)$ model. According to the data analysis of ARIMA (p, d, q) as shown on Table 3 and 4, the model estimation of autoregressive AR(1), differencing (3), and moving average MA(1), are exhibited as follows:

$$
\begin{aligned}
\operatorname{ExCof}_{t}= & 0,1105-1,5125 \operatorname{ExCof}_{t-1}- \\
& 0,9208_{\varepsilon-1}+\varepsilon_{t}
\end{aligned}
$$

The model is confirmed to fit both the AR(p) and MA(q) parameters with a significant $p$-value of less than 0.0001. Equation (4) is further interpreted by holding all variables on a fixed average and forecasting that share prices are going to decrease by 0.11 . A decrease by 1 unit of Cofext-1 in AR(1) estimation tends to have an effect of 1.51 on MA(1) and another variable constant on average. Conversely, when both AR(1) and constant estimates are fixed, its MAå1 decreases the average by 0.92 . Therefore, the model is used to predict the share prices volatility of ExCof for the next 12 months, which is tabulated and graphed as follows.

Table 5 and Figure 5 show a gradual increase for forecasting the data of exported coffee for the next 12 months. However, on the basis of statistics, the confidence interval is becoming wider over the forecasted dates. This means the

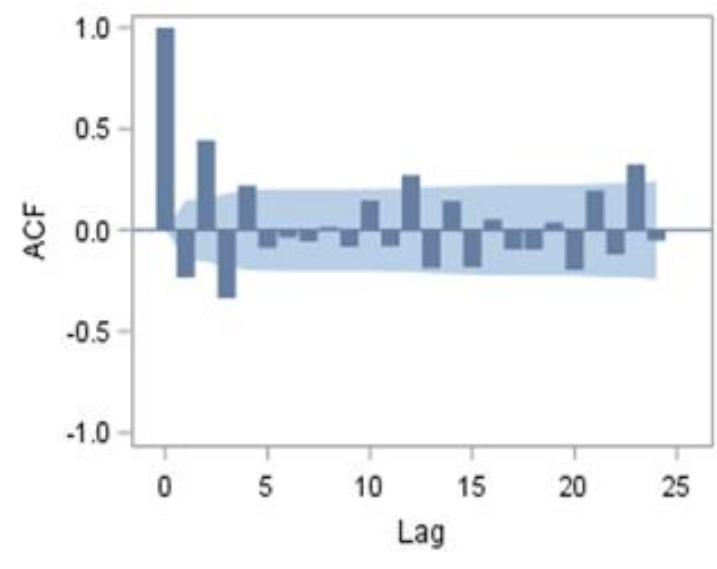

a

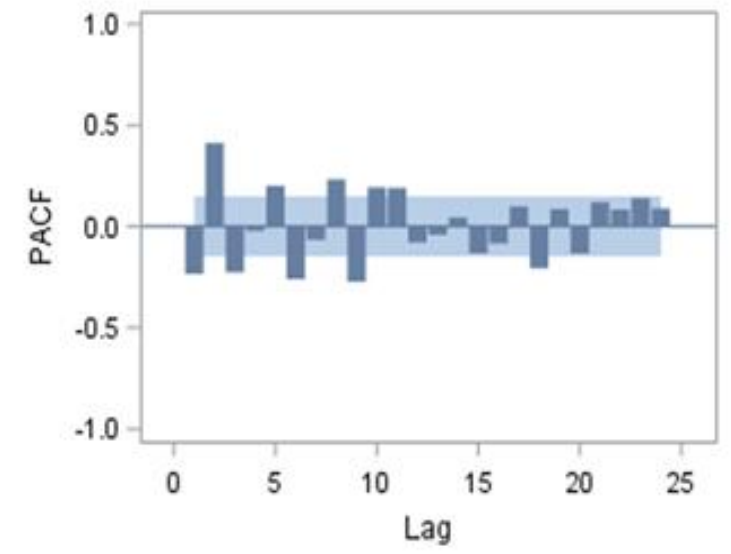

b

Figure 4. Plot of (a) ACF and (b) PACF After Differencing 3 (d=3)

Table 2. ADF Unit Root Tests After Differencing $3(\mathrm{~d}=3$ )

\begin{tabular}{lccccccc}
\hline Type & Lags & Rho & Pr $<$ Rho & Tau & Pr $<$ Tau & F & Pr $>$ F \\
\hline Zero Mean & 1 & -67.2306 & $<.0001$ & -5.76 & $<.0001$ & & \\
Single Mean & 0 & -67.2504 & 0.0013 & -5.75 & $<.0001$ & 16.52 & 0.0010 \\
Trend & 1 & -67.5601 & 0.0005 & -5.75 & $<.0001$ & 16.51 & 0.0010 \\
\hline
\end{tabular}

Table 3. Conditional Least Squares Estimation Parameter for Model ARIMA $(1,1,1)$

\begin{tabular}{cccccc}
\hline Parameter & Estimate & Standard Error & t Value & Approx Pr $>|\mathbf{t}|$ & Lag \\
\hline MU $^{*}$ & 0.58818 & 0.65194 & 0.90 & 0.3682 & 0 \\
MA1,1 & 0.92080 & 0.03937 & 23.39 & $<.0001$ & 1 \\
AR1,1 & 1.51246 & 0.05677 & 26.64 & $<.0001$ & 1 \\
\hline
\end{tabular}

*) MU is mean term 
Table 4. ARIMA Model Statistical Estimation

\begin{tabular}{lc}
\hline Constant Estimate & 0.11 \\
\hline Variance Estimate & 384.10 \\
\hline Std Error Estimate & 19.60 \\
\hline AIC & 1594.73 \\
\hline SBC & 1607.52 \\
\hline Number of Residuals & 181 \\
\hline
\end{tabular}

Table 5. Forecasts for Variable ExCof

\begin{tabular}{clllr}
\hline Obs & Forecast & Std Error & \multicolumn{1}{c}{$\mathbf{9 5 \%}$ Confidence Limits } \\
\hline 185 & 63.84 & 19.60 & 25.43 & 102.25 \\
186 & 72.17 & 22.77 & 27.53 & 116.80 \\
187 & 72.19 & 23.09 & 26.94 & 117.44 \\
188 & 74.26 & 28.81 & 17.78 & 130.73 \\
189 & 81.15 & 29.31 & 23.70 & 138.59 \\
190 & 78.59 & 29.58 & 20.62 & 136.56 \\
191 & 77.75 & 31.17 & 16.66 & 138.85 \\
192 & 82.07 & 31.17 & 20.96 & 143.16 \\
193 & 77.64 & 32.05 & 14.81 & 140.46 \\
194 & 75.78 & 33.18 & 10.75 & 140.82 \\
195 & 79.86 & 33.18 & 14.82 & 144.89 \\
196 & 75.80 & 33.68 & 9.78 & 141.81 \\
\hline
\end{tabular}

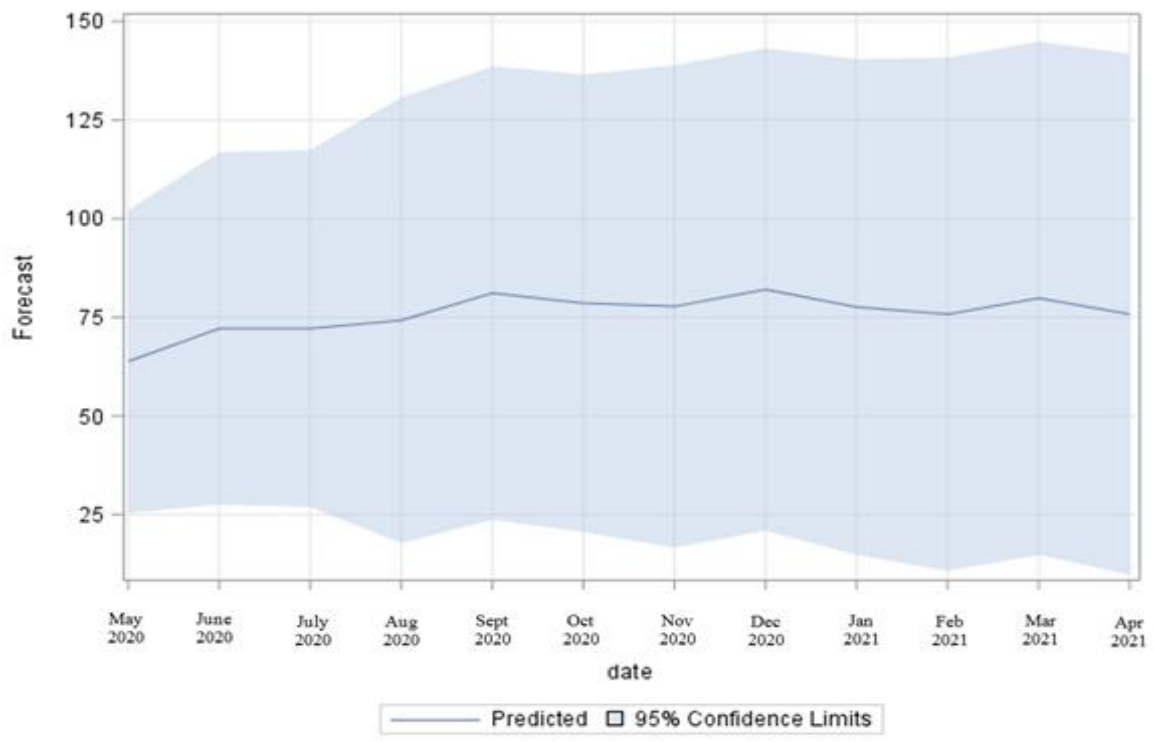

Figure 5. Forecasts for Excof Data

volatility of prediction is quite high relative to the interval limits; hence, it might be less accurate if longer period is applied.

\subsection{Social Economic Implications}

The large number of coffee export Indonesia can be competing in global markets. Indonesian has 


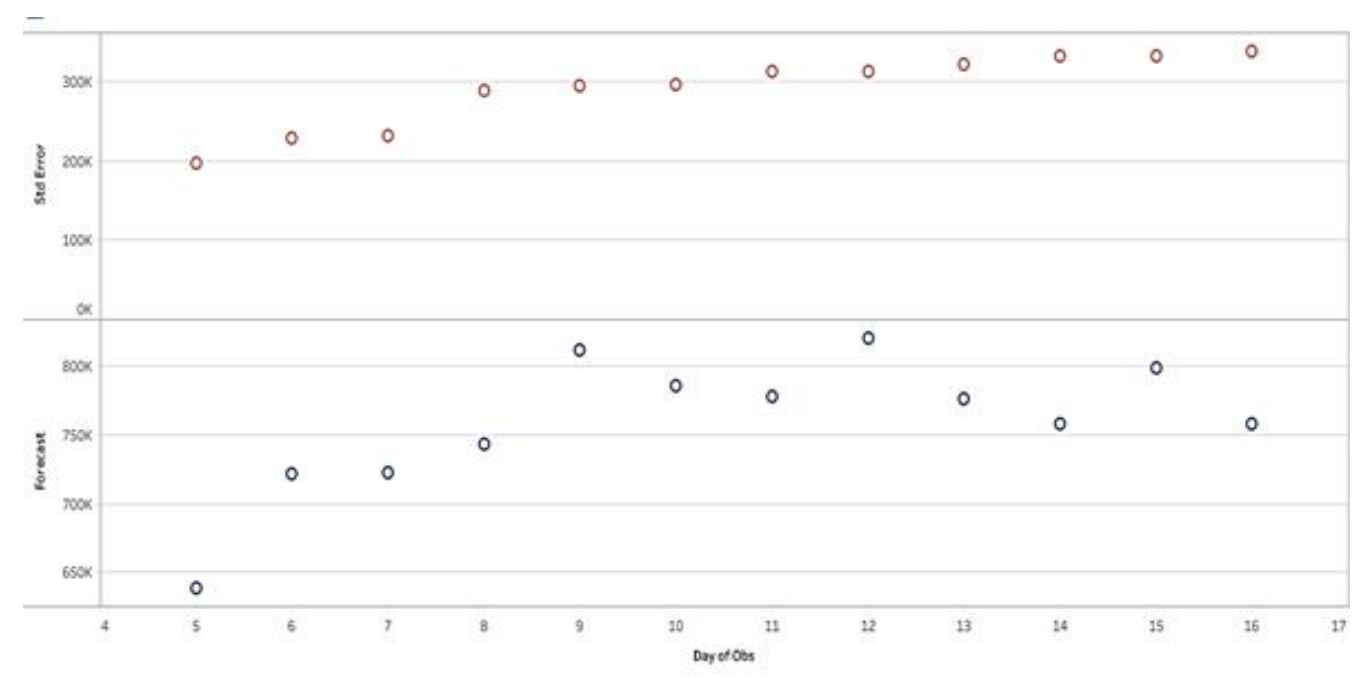

Figure 6. Fitted Std Error with Its Prediction Pattern

coffee varieties, where Robusta is the biggest. The productive lands for coffee is considerably large, which place Indonesia as the third largest coffee land in the world, shown on Figure 6. Furthermore, Figure 6 shows what has been analysed from statistical test for value export of coffee in Indonesia. The gradual increase pattern with a relative small error is fitted with the forecasting trend.

Socially, this study is to design the alignments to the coffee farmers in Indonesia. Previous studies found that farmers suffered loss as their limited knowledge about added value of coffee in global markets. Ponte (2002) showed the shifting on consumption pattern and governance structure of commodity chains that has caused a decreasing income on producer countries, while a soar increase of benefit earns on international roaster companies. With a future projection on export value of coffee, it may be a benefit for all parties, particularly for farmers to set strategy by holding the productions at price experiencing a downward trend.

\section{CONCLUSION}

As one of largest coffee producers in the world, understanding more deeply about the movement of export value of coffee (ExCof) is critical, particularly for coffee producers. Thereby, ARIMA model was selected to forecast the series of data of ExCof is ARIMA(1,3,1). However, before the analysis was conducted, the values of $\mathrm{p}, \mathrm{d}$, and q were first estimated to ensure the series' were stationary. The data obtained from January 2005 to April 2020 showed that they are not stationary, so a differencing order of 3 is applied to transform it into stationary. The stationary model of $\operatorname{ARIMA}(1,3,1)$, is used to determine a well-behaved construct and export value volatility due to its significant level of confidence, which is low $(<0.0001)$. Therefore, this model has an ability to forecast for the following month. With this prediction model, certain parties may benefit by taking a strategy holding or selling at accordance of current coffee prices.

\section{REFERENCES}

Azhar, R., Kesumah, F. S. D., Ambya, Wisnu, F. K., \& Russel, E. (2020). Application of shortterm forecasting models for energy entity stock price: evidence from Indika Energi Tbk, Jakarta islamic index. International Journal of Energy Economics and Policy, 10(1), 294-301. https://doi.org/ $10.32479 /$ ijeep.8715

Brockwell, P., \& Davis, R. (2002). Introduction to Time Series and Forecasting (2nd Edition). Springer-Verlag.

Brockwell, P. J., \& Davis, R. (1991). Time Series: Theory and Methods (2nd ed.). SpringerVerlag.

Chen, J., Wang, W., \& Huang, C. (1995). Analysis of an adaptive time-series autoregressive 
moving-average (ARMA) model for shortterm load forecasting. Electric Power Systems Research, 34(3), 187-196.

Moghram, I., \& Rahman, S. (1989). Analysis and evaluation of five short-term load forecasting techniques. IEEE Transactions on Power Systems, 4(4), 1484-1491.

Montgomery, D., Jennings, C., \& Kulachi, M. (2008). Introduction Time Series Analysis and Forecasting. John Wiley \& Sons, Inc.

Oxfam, B. O., Charavat, C., \& Eagleton, D. (2001). The coffee market: A background study. Oxfam.

Ponte, S. (2002). Latte Revolution? Regulation, markets and consumption in the global coffee chain. World Development, 30(7), 1099-1122.

Sampson, M. (2001). Time Series Analysis. Loglinear Publishing.
Tsay, R. S. (2014). Multivariate Time Series Analysis with $R$ and Financial Applications (D. J. Balding, N. A. Cressie, G. M. Fitzmaurice, H. Goldstein, I. M. Johnstone, G. Molenberghs, D. W. Scott, A. F. Smith, R. S. Tsay, \& S. Weisberg (eds.). John Wiley \& Sons, Inc.

Virginia, E., Ginting, J., \& Elfaki, F. A. M. (2018). Application of GARCH Model to Forecast Data and Volatility of Share Price of Energy ( Study on Adaro Energy Tbk, LQ45 ). International Journal of Energy Economics and Policy, 8(3), 131-140.

Wei, W. (2006). Time Series Analysis: Univariate and Multivariate Methods (2nd ed.). Pearson.

Xiong, T., Li, C., Bao, Y., Hu, Z., \& Zhang, L. (2015). A combination method for interval forecasting of agricultural commodity futures prices. Knowledge Based System. 